\title{
Visualizing Global Socio-Technogenic Human Transformation: Digital Challenges of Living Earth*
}

\author{
Elena Dergacheva ${ }^{1[0000-0003-4562-2914]}$ and Eduard Demidenko ${ }^{1[0000-0002-2113-6025]}$ \\ ${ }^{1}$ Bryansk State Technical University, Bryansk, Russia \\ eadergacheva20130yandex.ru
}

\begin{abstract}
In the XXI century, the world of man and nature develops mainly in socio-technogenic living conditions. Global technospherization of the planet Earth is the most important cause of continuous socio-cultural, techno-medical and biological changes in man. In technical, natural and human studies a human is usually considered from the point of view of only one discipline. This narrow approach leaves its incorrect mark when recreating the new image of a human in the virtual environment of the digital image of the world. Digital Earth technologies establish a link between the spheres: social, biospheric, natural-inanimate and artificial, created by society using a number of important sciences. It is necessary to approach systematically the representation of the evolving human being in the constantly updated digital space of the planet, to supplement the existing developments of scientists with a scientific and philosophical understanding of the interdisciplinary processes of socio-technogenic development of the biosphere life. Scientific visualization of interrelated evolutionary changes in man is of great interest for the Digital Earth project both from the point of view of studying anthropogenesis, and from the point of view of developing promising programs for preserving his biosphere body and natural health in a developing socio-technogenic world.
\end{abstract}

Keywords: Human, Biosphere, Artificial and Natural world, Socio-techno-natural Processes, Virtual Reality, Change of Evolution of Life.

\section{Introduction}

Social and natural world is now changing dangerously due to the spontaneous introduction of achievements of scientific and technological revolution. The expectations of the unilateral ruling economic and political elite of the strategic development of mankind are associated with the prospects of obtaining gratuitous wealth and the introduction of the digital revolution. Its technologies are aimed at system processing of the

Copyright (C) 2020 for this paper by its authors. Use permitted under Creative Commons License Attribution 4.0 International (CC BY 4.0).

* The publication of the conference proceedings was supported by the RFBR, grant No. 9-0320113. 
information accumulated by all mankind about the "biophysical objects" of the environment in the virtual space, which will allow artificial recreating a complete image of the real earth world in detail. The Digital Earth project, declared by Albert Gore at the end of the twentieth century, as a key task of information technologies of the twenty first century [1], aimed at creating a multi-dimensional information system as a platform to support international cooperation in order to solve global and local problems of the new world development [2]. The first achievements in implementing this project were made by Google developers in 2005. The Digital Earth project was officially approved by the Russian Government in 2017 [3]. This project does not take into account the more important and promising project - "Living planet", which no one takes, because it requires huge investments.

Subsequent paragraphs, however, are indented.

At the same time the precursor of discussing digital visualization of the planet should be considered the following novels: "The Master and Margarita" by M. A. Bulgakov (1928-1940) and "War and Peace" by L. N. Tolstoy (1869) [4]. They were the first to consider "live" globes with fantastic for that period opportunities for studying terrestrial objects in dynamics. These time-anticipating globes had the characteristics of an allscale, all-angle, and unsigned representation of the constituent elements. A foreign researcher D. Jackson (2018) associates the first publications about the representation of the Earth's globe in a new volume quality with the works of R. B. Fuller (1928) [5]. Research shows that the foresight of the Digital Earth in Russia began almost a century and a half before the famous speech by A. Gore about the need to develop a qualitatively different system for presenting geospatial information (1998), which is recognized in the international publications [6].

In 1995 professor E. S. Demidenko proposed the project "World Information Encyclopedia" of multimedia content, supported in the Declaration of the United Nations, the International Academy of Informatization, the Administrations of Moscow region and Dubna (Russia), providing regionally quality assessments of all objects and processes of world development on the basis of certification systems for quality and ecology. Its part is already being worked out in Kaliningrad region, and this may find applied in the development of the project under discussion [7].

In engineering sciences, the "live" globe of the Digital Earth is identified with a dynamic pulsating system of representing geoinformation data outside the scales of traditional maps. In contrast to the narrow technical interpretation the concept of "Living Earth" developed by us in this and other papers, combines various phenomena of natural biological life, cultivated by millions of years of biosphere evolution, including man himself as a biosocial organism. This paper deals with filling the virtual space of a digital planet with more than just geoinformation data. This refers to an extended model of recreating the biosphere in virtual space in relation to social, natural and technological processes affecting the modern evolutionary development. And man is an integral element of these processes, whose visualization in the dynamic artificial environment of a virtual planet seems necessary. This paper continues the topic of visualization of evolutionary socio-technogenic processes, raised in an earlier work by one of the authors of the paper [8]. After all, if there are people in the virtual "Voland's globe" from Bulgakov's novel "The Master and Margarita" [9, p. 268], then in order to reproduce a 
real copy of the Earth in digital space, it is necessary to present the historical perspective of the evolutionary changes that occur to man. Visualization of global socio-technogenic changes in man is a digital challenge to information technologies to recreate in detail the processes of the Living planet, that is the biosphere system of life in the unity of society, man and nature. To implement this idea in the digital space, an interdisciplinary symbiosis of information technologies with natural and social sciences is necessary. It is quite possible that we are talking about the construction of a «time machine», since the Digital Earth project will allow us to model retrospective and prospective processes in visual images.

The project implemented by various international research groups involves complex mapping of the Earth's surface, including social and cultural objects [2]. Digital Earth is a "visual phenomenon", that is, a geo-information system built on multidimensional high-quality visual images. In contrast to the existing maps, Digital Earth (or neogeography in terms of Russian researchers [10]) provides an interactive, out-of-scale, allangle view of heterogeneous objects, including adjustments to the viewing distances of images [11].

As the developers of the Digital Earth project from different countries hope, this virtual environment should reflect the image of the real world, both social and natural [12]. Visualization of the planet in the virtual space also implies a systematic representation of man as a representative of not only terrestrial, but also digital world. In the conditions of socio-technogenic development of life and world, man is subjected to many-sided socio-cultural, technological and natural-biological transformations [13, $14,15,16]$, this makes it necessary to take them into account when reproducing his unfavorably changing image in an increasing artificial environment.

\section{Methodology}

In our research, we initially rely on a systematic socio-natural approach, discovered by V.I. Vernadsky. Biosphere over the entire history of life has not only developed itself, but has also transformed the entire surface of the planet, creating man. Now society is even more transforming not only the world, but the biosphere itself. V.I. Vernadsky, relying on the centuries-old experience of farmers in cultivating plants and domesticating animals, strongly believes that associated humanity will continue to form a higher level of biosphere, which corresponded to his understanding of noosphere [17, p.175]. But the bourgeois organism developing on the scientific and technological basis of private property affects the biosphere nature (including man) not so much by changing it positively, as by negatively transforming and destroying it. Visualization of changes in biosphere and man is important for the purposes of retrospective and prospective analysis of the Earth state.

Nowadays philosophers and scientists rely more and more on the use of interdisciplinary research to determine the fundamental laws of the world's development. In our approach to interdisciplinary research of the socio-technogenic development of the world and the change in the evolution of life, philosophy plays the leading role. Its multidisciplinary approach is based on the essence of philosophy, which covers not only the scientific side of life, but also a significant area of non-scientific knowledge, social experience of mankind, socio-cultural 
values developed by it, especially the principles of morality [18]. Together, these elements make up an important tool of post-non-classical philosophy and science, and allow to trace how technogenic life is developing now and how it will change humanity in the future [19]. This also allows us to understand the phenomenon of the Digital Earth being formed in a multidimensional way. A virtual image of it is created on the basis of the tools of technical sciences $[10,11,20,21]$, but the existing image of a deadly transforming living planet is overlooked.

\section{$3 \quad$ Results and Discussion}

Digital Earth is a kind of virtual image of a globe of multi-contour socio-economic, ecogeographic and other data, combined with appropriate algorithms for their analysis and models. The mechanism of constantly updated data in a high-performance computing environment allows to see the state of the Earth's systems (atmosphere, hydrosphere, lithosphere) in their historical dynamics, monitor changes, and build a probable forecast for the future. This project is of an interdisciplinary nature, since, on the one hand, it is filled with data from observations of various sciences and connected by a network of digital libraries. On the other hand, eventually system analytics represented by visual models is more easily perceived by scientists from different research fields. Data visualization technologies provide a visual representation of social and natural processes taking place in the world. This approach formally allows to apply the information obtained in the natural, social and technical sciences jointly, make sciencebased decisions, and in the future - to strengthen control over the state of subsystems of Earth's biosphere. All this confirms the fact that the Digital Earth establishes a connection between the worlds: social, biospheric, naturally inanimate and artificial, created by society using a number of important sciences, but, in our opinion, far from scientific, since it ignores the foundation of scientific knowledge i.e. philosophy, reducing it to a worldview discipline.

In the guide to Digital Earth published at the end of 2019, which fully reflects the research developments related to this topic, man is presented in the aspect of studying social and behavioral activity in the virtual space. According to a number of researchers, it is necessary to focus on this aspect of man's life, which is associated with the activities and interests of many users in social networks, when building an image of man in the digital space. Visualization of behavioral models of network users (leaving "digital traces") will allow not only to build marketing strategies and provide economic justification for planned activities in the virtual environment, but also to predict and even prevent social disasters, to understand the relationship between the environment and individual's behavior. After all, man at his pages in social networks shares feelings and emotions about events from the real world in an iconic form [22]. Therefore, the study of psychological aspects and the construction of man's changing socio-cultural image that corresponds to them is quite justified from the point of view of the perspective safe development of a social, technical and biospheric society, in which the biosphere will exist as a self-developing system.

As a result of the spontaneous socio-technogenic development of the world, homo sapiens himself changes in many ways spontaneously as a biosocial being, whose life 
activity is mainly connected with the growing techno-urban environment of life. Natural man, nurtured by millions of years of biosphere evolution, undergoes transformations in the technosphere environment of life in three spheres: socio-cultural, natural-biological and artificial-technogenic. We believe that visualization of interrelated evolutionary social, technical and natural changes in the human is of great interest for the Digital Earth project, both from the point of view of studying anthropogenesis for scientific and educational purposes, and from the point of view of developing promising programs for preserving his biosphere body and natural health in a dynamically developing socio-technogenic world.

In accordance with the historical stages of socio-technogenic formation of the world, we distinguish two epochs in the existence of mankind: 1) the epoch of biospheric humanity, which combines social systems: a) gathering, b) agriculture and crafts; 2) the epoch of post-biosphere (technogenically developing) humanity, including c) industrialtechnogenic, d) post-industrial-technogenic (information-technogenic) society. The concept of D. Bell considers three societies on the basis of changes in the technical and technological way of production of social life: agrarian, industrial and post-industrial (informational). This division gives a different understanding of societies, in which only social laws are taken into account, and changing natural processes due to socio-technogenic development are left out of consideration. We extend understanding of the societies proposed by D. Bell, and add their characteristics with the consideration of sociotechnical and natural evolutionary changes. On this basis, we consider societies as industrial - and post-industrial-technogenic (Fig.1).

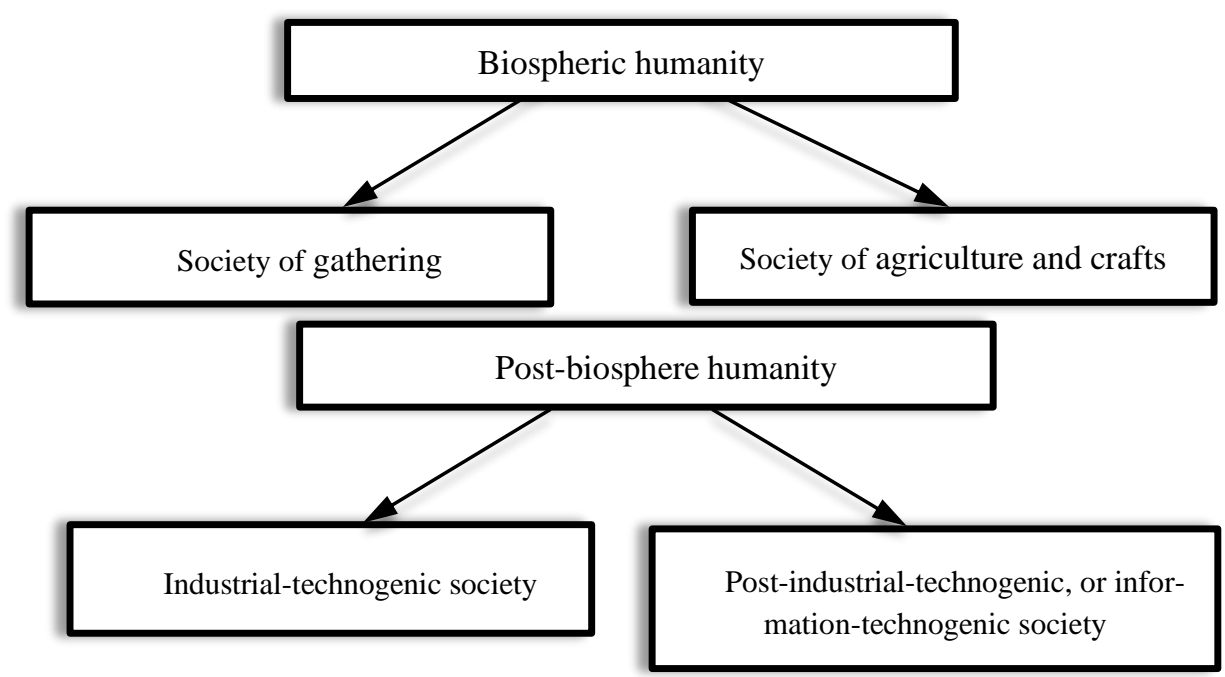

Fig. 1. Classification of humanity types depending on the historical stage of socio-technogenic development of the world.

We should also note that D. Bell, being a Marxist, ignored Marx's research on the class division of social systems. This is especially true for bourgeois and socialist 
industrial and technogenic development, without which we cannot combine the projects of Digital and Living Earth.

The global anthropogenesis is associated with the appearance and development of primitive people. First there appeared homo sapiens -Neanderthal man (about 400 thousand years ago), then - Cro-Magnon man (about 200 thousand years ago), and 50-60 thousand years ago there appeared a modern man based on Cro-Magnon with traces of Neanderthal genes. For thousands of years, the evolution of society has been in organic unity with nature. Its life activity, corresponding to the appropriating type of economy, completely fit into the chain of the biotic cycle of substances. During that period, evolutionary changes in man were of biospheric and biological nature: there was a formation of races and the division into blood groups. But the resources of cropping and gathering were exhausted, so humanity was forced to switch to agriculture (as the first type of producing economy) and the use of natural, biospheric (i.e., agricultural and breeding) technologies. Neolithic revolution (approximately 10 thousand years ago) was the end of the era of human existence as an ordinary animal species, since it marked the transition from an appropriating to a producing economy (agriculture and craft) with a noticeable formation of the technosphere and technogenic type of life development. Society began to change the biogeochemical cycles of nature purposefully and to create an artificial cycle of substances using manual technologies, although just on small territories at that period. But these changes have not yet led to the emergence of a technogenic society and to significant technogenic transformations in biosphere and man. All these and many other facts give reason to believe that the societies of gathering and farming should be attributed to the epoch of existing biospheric humanity (i.e., natural, evolutionarily nurtured by nature).

A society consisting of people is a subsystem of biosphere that has been evolving over many millennia in the biosphere system of life. About three centuries ago, during the transition to industrial-technogenic development, the dominant role in the relationship "society-nature" began to shift to a technogenic society, which significantly reconstructed the natural environment of life, creating an artificial one.

The industrial revolution (XVIII century) created conditions for a radical transition of society to the mass socio-technogenic development of biosphere and machine-technical subordination of nature to the technogenic society in the XIX - XXI centuries, which led to the mass destruction of biosphere. For example, in 1920-1970s, the discharge of humus from the soil covering into rivers, seas and the ocean increased from 3 billion tons to 24 billion tons [23]. Technogenically developing society based on a variety of industrial nano-, bio-, information, cognitive technologies creates an artificial object, tool, material and electromagnetic environment of life, that is technosphere, technogenically transforms biosphere, its natural and biological processes and organisms. In the third decade of the XXI century $n$ the urban technosphere about 4 billion people will live, that is more than half of the world's population, whereas in 1800 there were only about 50 million people [24]. A rational technosphere system of life is being formed, into which society gradually translates all the processes of biotechnological reproduction of life. Transitional "rational" forms of life between the natural and artificial worlds are a variety of biotechnological, cloned organisms, including man who is technogenically changing as well. 
There is integrated interdependence of the whole socio-economic, technosphere and biosphere development, which eventually results in expansion of processes of the world social and technological development, technogenic transformation of the biogeochemical cycles of substances, and more generally - in changing the direction of the land surface evolution - from biosphere to post-biosphere, mostly artificial [13]. These and other questions of post-biosphere biotechnological development of life in the urban technosphere and the formation of post-biosphere humanity attract a lot of attention of scientists and researchers of the Russian Interdisciplinary Scientific-philosophical School which deals with social and technological development of the world, social and technological processes and changes of life evolution, working at Bryansk State Technical University since 2002 [18]. If we try to analyze the transition of life from biosphere into urban technosphere, then we will get the following facts: in 1860 technosphere contained 5\% of the world's animals, including humans, in $1940-10 \%$, in 1980$20 \%$, and now- $40 \%$, which clearly indicates the formation of post-biosphere life on Earth's land [13] (Fig.2).

Intensification of processes in social, technological and natural development of the world indicates that the Digital Earth project is a valuable and logical reflection of the global technologization of all life processes in biosphere, and then it can also serve as a kind of big data library of created technosphere. In the created technosphere, two components should be distinguished - the post-biosphere world (physically tangible, technospheric) and the off-biosphere world (virtual, supplemented by the imagination of people, symbolic, described by technical means of information technologies). Virtual tools (information technologies) can be considered as info-technosphere [25], which ensures the functioning of technosphere development of life.

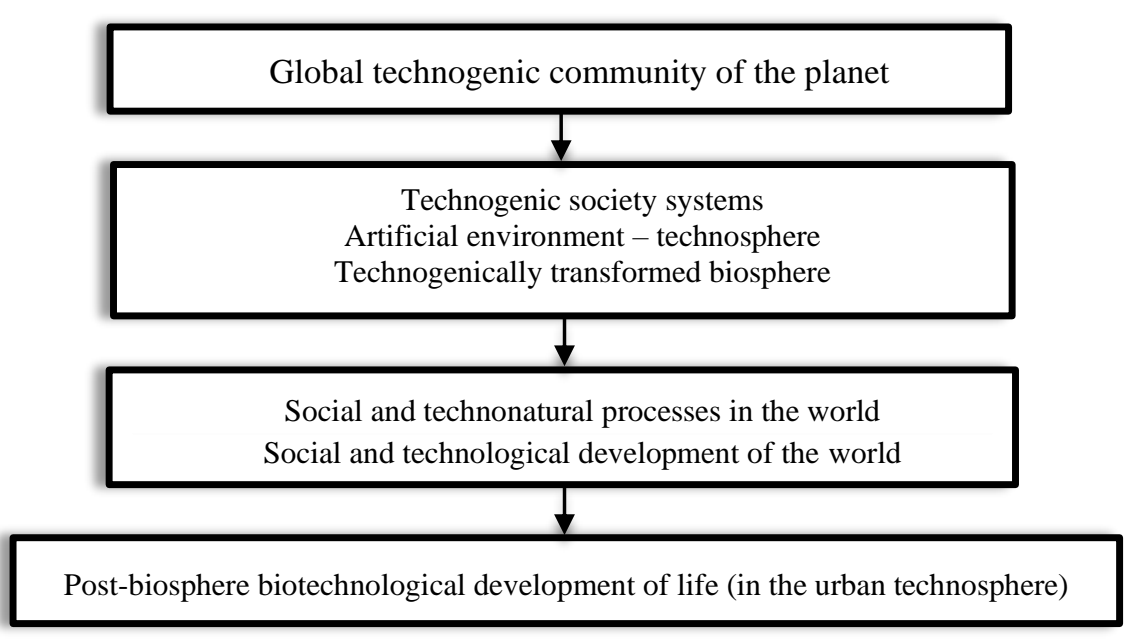

Fig. 2. Global technogenic community of the planet which leads to the degradation of biosphere components.

To maintain the functionality of non-material, virtual space, a significantly increasing amount of electricity is consumed in the biophysical world. Technosphere, 
connecting with a technogenically developing society and technogenically transformed regions of biosphere, forms a semi-artificial (i.e., transitional to artificial) social, technical and natural system of life. Technogenic transformations happening to man include both changes in his social qualities in life, and purposeful changes of the body by social, technical and medical interventions, as well as the impact on the body with synthetic chemicals produced by society, located in the atmosphere of cities and food, weakening of his physical health as a result of leaving the sphere of natural selection and as a result of a sedentary lifestyle (Fig. 3).

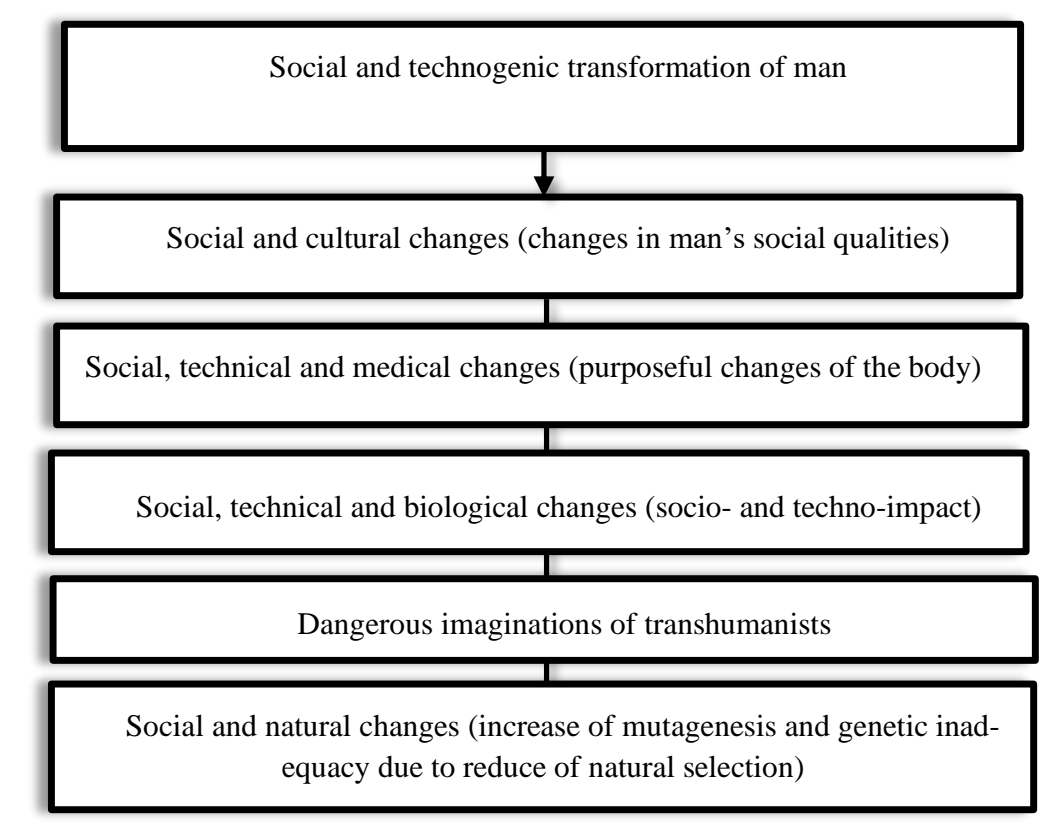

Fig. 3. Global social and technogenic transformations of man.

In the agricultural society, the main socio-natural qualities of man were: workaholism, conciliarity, collectivist morality with primary spirituality, kindness, honesty, trust, compassion, tolerance, empathy, forgiveness, faith in the supernatural and powerful things, justice, love, protection of wildlife, limited ideas about the world and knowledge of life, low average life expectancy, high mortality of children, extreme poverty of the absolute majority of the world's peoples, naturally defined health and its strengthening by sports and medicine. The highest meaning of life was love for close people and divine symbols. Creative achievements in activities and agricultural culture were the following: cultivation of higher types of plants, domestication of animals, creation of unique religious buildings and cultural monuments, folk festivals and useful leisure activities (Fig. 4).

Over the millennia, the average life expectancy has changed as the main indicator of the level of socio-historical development and the state of natural and biological viability of man (Table 1). So, if in Russia the average life expectancy in 1897 was 32 years, in 
1990 in the USSR-70 years, in 2020 -71 years [24]. According to WHO, life expectancy in the world is 67.2 years ( 65.0 for men and 69.5 for women) according to the UN, in Japan -84 years, in socialist Cuba -79 years, in the United States -78.5 years.

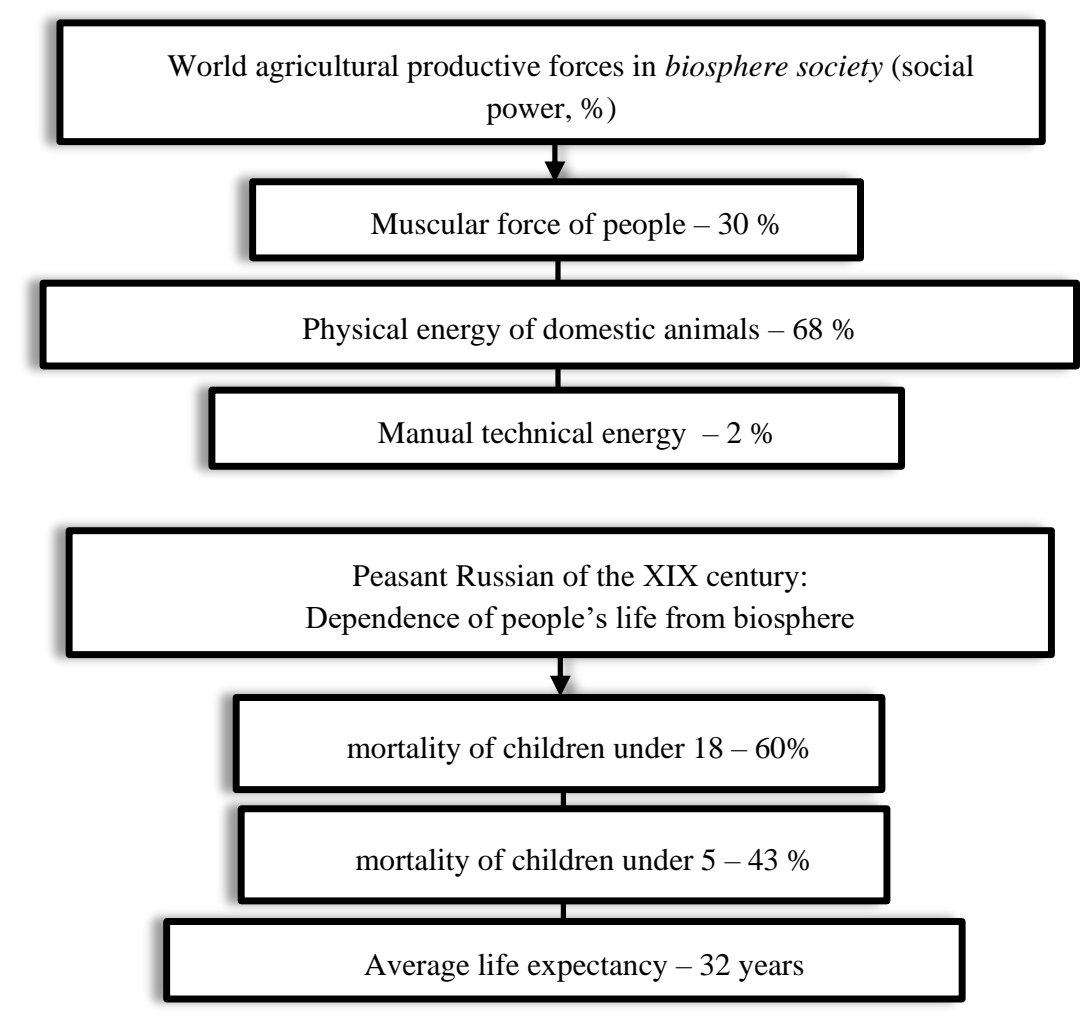

Fig. 4. Total social energy and life expectancy of biosphere humanity.

The main socio-natural qualities of man and people's relations in a technogenic socialist society (the USSR and China) in the conditions of socio-collective orientation of life, socio-natural and humanely developing consciousness (mind) was the predominance of national socio-natural values, such as: workaholism, conciliarity, socialist morality and spirituality, kindness, honesty, trust, forgiveness, empathy, compassion, tolerance, faith in the supernatural and especially the powerful things, justice, a high level of culture, education and health of people, love and collective protection of nature, the average level of ideas about the world, knowledge about life, average life expectancy, low mortality of children, above average living standards of the entire population (Fig. 5), lack of exploitation, socially defined health on the basis of free medicine and sports, predominance of public funds and social justice, the highest meaning of life - love to the closest, to work, creating values. 
10 E. Dergacheva, E. Demidenko

Table 1. Retrospective and prospective analysis of changes in human life expectancy (according to WHO) [24].

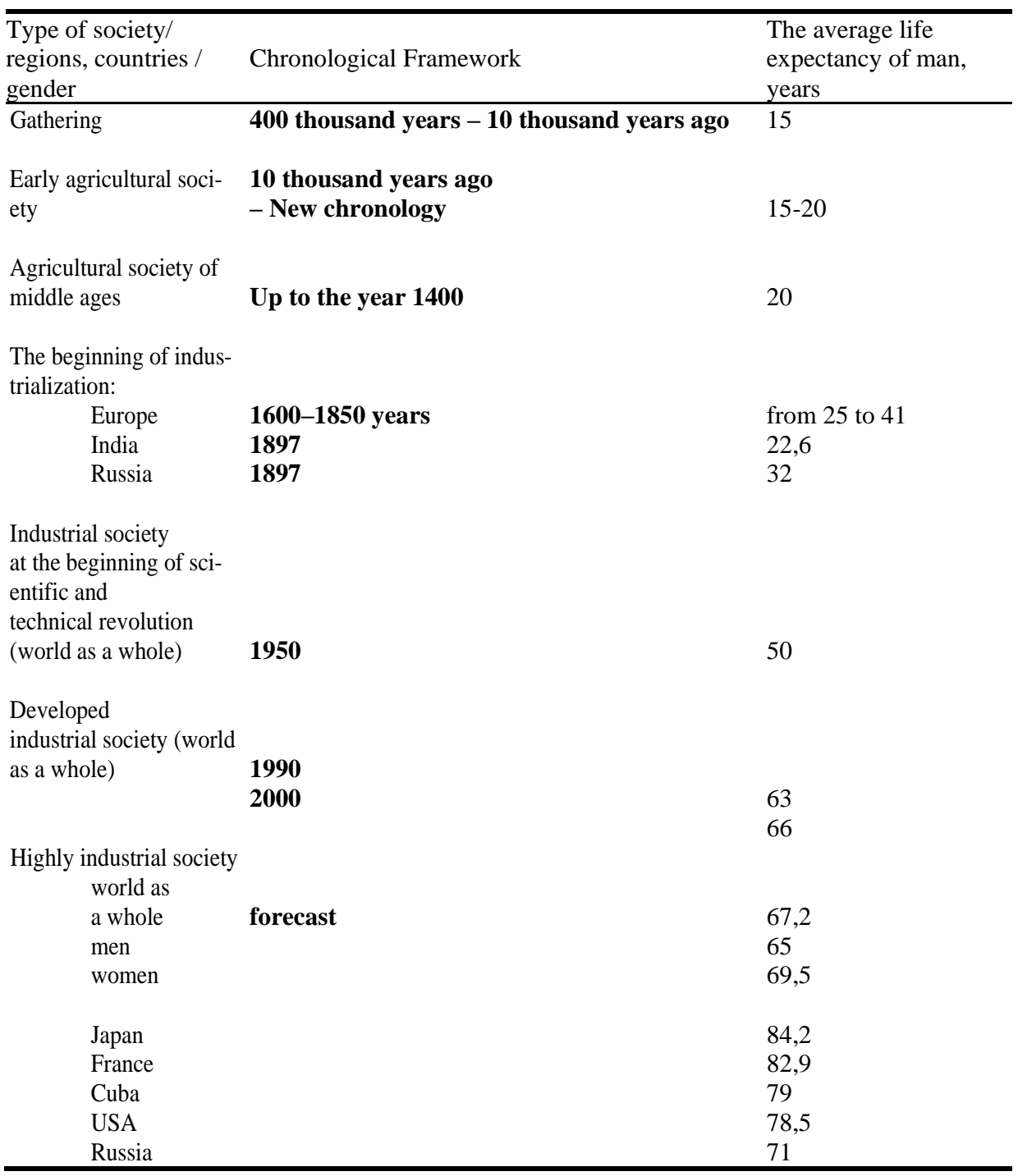

Creative achievements in collective activity and socialist culture of the USSR and China were creative development of culture as opposed to the bourgeois, high level of education of the population and higher education, high level of mastering the specialty, creative nature of labor, cultivation of higher types of plants, domestication of animals, creation of unique religious buildings and many cultural monuments, folk holidays and useful leisure activities. At the same time, this socio-historical stage is characterized by an excessive level of technogenic-industrial development: artificial forms of human life, urbanization and forming technosphere for people and animals, negative technological 
effects on biosphere life in cities and nature, destruction of soil cover as the basis of biosphere life, forming promising biotechnological production to replace biosphere forms of production and human life. Since the entire economy of a technogenic society is motivated by the rationality of effective income generation, then man develops qualities related to the search for individual benefits, high professionalism, and education.

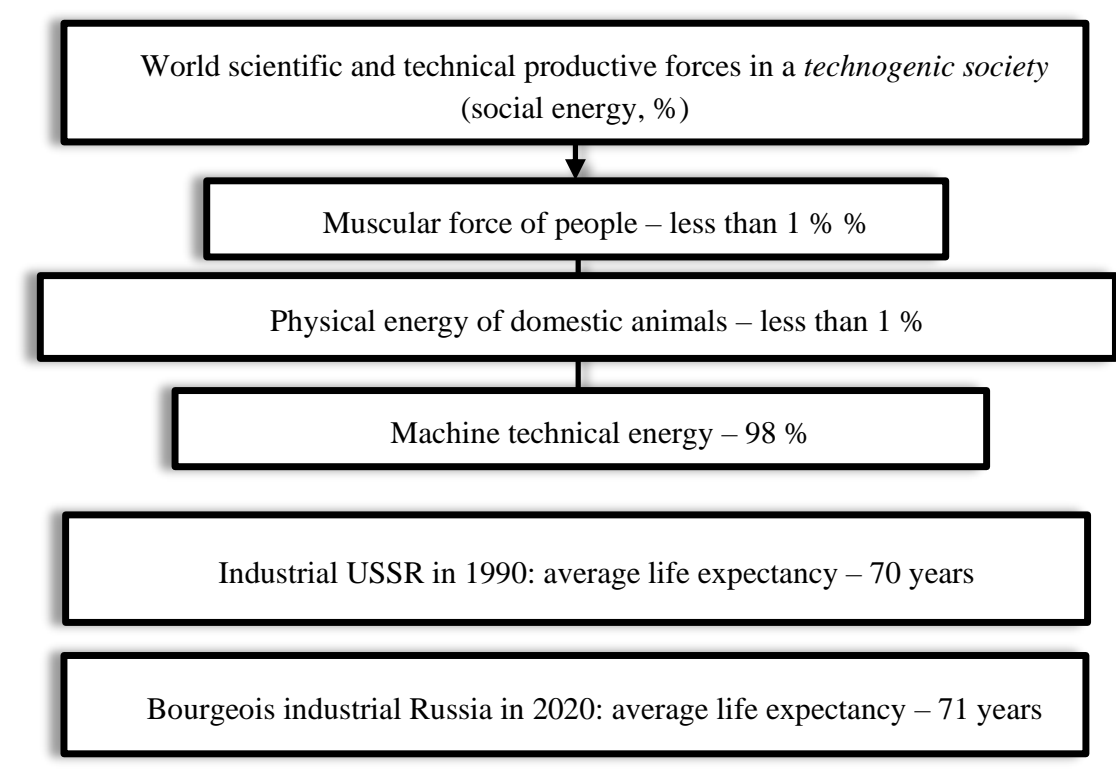

Fig. 5. Total social energy and life expectancy of technogenic mankind.

During global technospherization, man develops new, technogenic qualities (in particular, new norms of communication, habits, ideas about everyday life, having leisure, lifestyle, etc.) that replace natural ones. They are associated with scientific medical technologies for improving human nature and endowing the body with new properties, maintaining weakened health. On the other hand, the uncontrolled expansion of technomaterials in the biosphere adversely affects the health of an individual, which leads to the growth of allergic, oncological and other diseases of civilization [13]. So, three or four decades ago, according to WHO data, allergies were extremely rare. By the beginning of the XXI century in the conditions of intensive technogenic development the situation has changed: within a decade and a half since the beginning of registration of this disease (since the 1980s) in official sources, the number of allergic diseases in the world has doubled (in particular, those with bronchial asthma) and, as a result, weakening of the immune system [24]. All this indicates that technologies are becoming a factor that determines the change of social and biological processes in man, since they fix the irreversibility of trends and contain prerequisites for changing the direction of his evolution.

Strengthening of the era of the fourth industrial revolution proclaimed by the technocratic elite of the world [26] focuses the attention of researchers on the full technicalization of the human being, which is reflected in various projects of medical technologies to 
improve the quality of people's life, and in dangerous imagination of transhumanists to create and visualize an artificial analog of man [16]. But man represented as "the sum of technologies" (according to the apt phrase of the academician of the Russian Academy of Sciences V. A. Lectorskiy) [27, p. 86], devoid of feelings and emotions, controlled by both external and internal technical systems, already belongs to the post-human branch of evolution.

\section{Conclusion}

The main task of modern society is to preserve the natural man in the conditions of spontaneously increasing socio-technogenic development of the world, to preserve biosphere necessary for his life. Complementing the thoughts of Yu.N. Golubchikov about threats to biosphere development, we can say that the development of strategies for the survival of natural humanity is becoming the most important "new geoconcept of geography" [28], implemented in the project Digital Earth.

Socio-technogenic transformations, considered in the paper, are largely spontaneous. It is necessary to include them into the content of the virtual environment of the Digital Earth. A systematic representation of the evolutionarily changing appearance of a human being in an artificial environment is important from the point of view of developing all promising programs for preserving his biosphere body and natural health in a highly transforming and perversely developing socio-technogenic world. Effective decision - making to maintain human viability depends directly on the quality of percepting the context in which these decisions are made. The context in this case is the geospatial space of the Digital Earth.

The quality of virtual geospatial management is determined by the quality of modeling social, technogenic and natural processes in it. Until recently, geospatial analysis was conducted primarily on the basis of data presented in traditional maps and geo-information systems. Information technologies of the Digital Earth represent a more perfect tool, because they avoid static images of the world and allow to see the world as it is in reality. With the help of scientific visualization tools, we are able to see "Living Earth "(biosphere) in a natural, alive way without the use of "dead" conventions (signs, models, categories) and plan programs for the safe socio-technogenic development of the world and man. The living world will be integrated into the decision-making procedure for managing socio-technogenic changes due to the immanent quality of virtual space - the natural character of reproducing processes modeled using the Digital Earth.

The modern world is only taking the first steps in scientific visualization of the human image in the Digital Earth [22]. Large-scale tasks for information technologies to represent the real image of the biosphere in an artificial environment have to be solved yet. These tasks can be implemented only if the entire interdisciplinary potential of natural, social, and technical sciences is involved. 


\section{References}

1. Gore, A. The Digital Earth: Understanding our planet in the 21st Century. Al Gore speech at California Science Center, Los Angeles, California, (January 31, 1998).

2. Liu, Z., Foresman, T., van Genderen J., Wang, L. Understanding Digital Earth. In: Guo H., Goodchild M., Annoni A. (eds) Manual of Digital Earth (2019). Springer, Singapore. https://doi.org/10.1007/978-981-32-9915-3_1, accessed 28-June-2020

3. Russian Cosmos. The Digital Earth project stimulates the growth of the Russian economy. https://www.roscosmos.ru/23571/, accessed 28-May-2020

4. Eremchenko, E.N. Prehistory of the Digital Earth concept. Geocontext: Scientific multimedia almanac, vol. 7, n 1. Dresden, Moscow (2019). http://www.geo-context.org/index.php/geocontext/article/view/47/46, accessed 28-April-2020

5. Jackson, D. Data Cities: A new book on architectural aspects of Digital Earth (2018). URL: http://www.digitalearth-isde.org/news/840, accessed 28-April-2020

6. Baturin Y.M. et al. (2020) Digital Earth in Russia. In: Guo H., Goodchild M., Annoni A. (eds) Manual of Digital Earth. Springer, Singapore. https://doi.org/10.1007/978-981-329915-3_23, accessed 28-April-2020

7. Demidenko, E.S. The world of inform-encyclopedia (since 1995). Kaliningrad. www.kaliningrad.wie.su, accessed 28-April-2020

8. Dergacheva, E.A. Visualizing Socio-techno-natural Processes: Issues and Challenges // CEUR Workshop Proceedings of the 29th International Conference on Computer Graphics and Vision (Graphicon 2019), vol. 2485, pp. 168-172. http://ceur-ws.org/Vol-2485/paper38.pdf, accessed 28-April-2020

9. Bulgakov, M. A. (1928-1940) Master and Margarita. Novel. ABC-classic, Saint Petersburg (2006). $406 \mathrm{p}$.

10. Eremchenko, E.N., Dmitrieva, V.T., Nikonov, O.A.: Cartography: between two paradigms. Geocontext: Scientific multimedia almanac, vol. 6, pp. 12-36. Dresden, Moscow (2018).

11. Eremchenko, E.N., Tikunov, V.S., Zakharova, A.A.: Digital Earth and «Digital» Initiatives of Modern Era. Proceedings of the 28th International Conference on Computer Graphics and Vision (Graphicon 2018). https://www.graphicon.ru/html/2018/papers/304-306.pdf, accessed 28-April-2020

12. Huadong, Guo, Goodchild, Michael F., Annoni, Alessandro (eds.) Manual of Digital Earth. Springer, International Society for Digital Earth (2019). https://doi.org/10.1007/978-98132-9915-3, accessed 28-April-2020

13. Demidenko, E.S., Dergacheva, E.A.: Biotechnological Processes in the Changing Evolution of Life on the Planet Earth. IOP Conference Series: Materials Science and Engineering, vol. 753, Issue 5, pp. 052066 (2020). DOI: https://doi.org/10.1088/1757-899X/753/5/052066, accessed 28-April-2020

14. Demidenko, E.S.: Ecotechnological apocalypse, or "doomsday" of a natural human (Report to the XIX World Philosophical Congress). Ochug, Bryansk (1993).

15. Popkova, N.V. Anthropology of technology: problems, approaches, prospects. Librokom, Moscow (2012).

16. Yudin, B.G.: Perspectives of man: between past and future. In: Man and his future: New technologies and human capabilities, pp. 44-57. Lenand, Moscow (2012).

17. Vernadsky, V.I.: Biosphere: thoughts and sketches. Noosphera, Moscow (2001).

18. Trifankov, Y. T., Dergachev, K. V.: A Brief Review of the Modern Development of the World and Life in the Works of Scientists of Bryansk Philosophical School of Social-Technogenic World Development. SHS Web of Conferences. RPTSS 2015 - International 
14 E. Dergacheva, E. Demidenko

Conference on Research Paradigms Transformation in Social Sciences 2015 (28), (2016). http://dx.doi.org/10.1051/shsconf/20162801151, accessed 28-April-2019

19. Philosophy of social interaction in the age of convergent technologies. Liseev, I.K. (ed.) (Institute of Philosophy of RAS). Nestor-History, Moscow, St. Petersburg (2018).

20. Nyrtsov, M.V., Nyrtsova, T.P.: Big Data in Cartography. Smart mapping: Future or technological changes // Bulletin of Universities. Geodesy and aerial photography, vol.5, pp. 4245 (2016)

21. Zakharova, A.A., Podvesovskii, A.G., Shklyar, A.V.: Visual and Cognitive Interpretation of Heterogeneous Data. Int. Arch. Photogramm. Remote Sens. Spatial Inf. Sci., XLII-2/W12, (2019) pp. 243-247. doi: 10.5194/isprs-archives-XLII-2-W12-243-2019, accessed 28April-2020

22. Ye, X., Zhao, B., Nguyen, T.H., Wang, S. Social Media and Social Awareness. In: Guo H., Goodchild M., Annoni A. (eds) Manual of Digital Earth (2019). Springer, Singapore. https://doi.org/10.1007/978-981-32-9915-3_12, accessed 28-April-2020

23. Kovda, V.A. Soil cover, agriculture and socio-ecological problems. Questions of sociology, pp. 149, 156. Lviv (1987).

24. World Health Organization, https://www.who.int/ru, accessed 28-April-2020

25. Lapchenko, N.N. Informatization of society in the conditions of technogenic socio-natural development: philosophical and legal aspects. Desyatochka, Bryansk (2009).

26. Schwab, K., Davis, N. Technologies of the Fourth Industrial Revolution. Eksmo, Moscow (2019).

27. Lektorskii, V.A.: Uncertainty and risk as a condition of human being. In: Belkina, G.L., Frolova, M.I. (eds.) Human World: Uncertainty as a Challenge, pp. 80-87. Lenand, Moscow (2019).

28. Golubchikov, J.N. Meta-texts of biospheric catastrophes. Geocontext: Scientific multimedia almanac, vol. 2, pp. 5-20. Dresden, Moscow (2014). 